\section{Verifiable CPD that will fit into your busy lifestyle}

A recent, pan-European study has revealed that as many as $41.9 \%$ of young adults suffer from dentine hypersensitivity. ${ }^{1}$ Due to the often sporadic nature of dentine hypersensitivity, patients may fail to mention it at the dental appointment. It therefore lies with the dental professional to identify this painful condition which can cause patients to neglect their oral hygiene. ${ }^{2,3}$

For the latest updates on the condition and to learn about a clinically proven innovation for dentine hypersensitivity treatment, Sensodyne Repair \& Protect, discover the new interactive Sensodyne with NovaMin distance learner module.

The module is free of charge, easy to use and available 24 hours a day. There's no time limit so you can complete the module whenever you like, in your own time and at your own pace. What's more, completion of the module can contribute up to 1.5 hours towards your verifiable CPD.

Visit www.gsk-dentalprofessionals.co.uk/pr to complete the module now.

1. West N X, Sanz M, Lussi A, Bartlett D, Bouchard P, Bourgeois D. Prevalence of dentine hypersensitivity and study of associated factors: a European population-based cross-sectional study. J Dent 2013; 41: 841-851.

2. Schiff T, Delgado E, Zhang Y P, Cummins D, DeVizio W, Mateo L R. Clinical evaluation of the efficacy of an in-office desensitizing paste containing $8 \%$ arginine and calcium carbonate in providing instant and lasting relief of dentin hypersensitivity. Am J Dent 2009; 22 Spec No A: 8A-15A.

3. Schiff T, Delgado E, Zhang Y P, DeVizio W, Cummins D, Mateo L R. The clinical effect of a single direct topical application of a dentifrice containing $8.0 \%$ arginine, calcium carbonate, and 1,450 ppm fluoride on dentin hypersensitivity: the use of a cotton swab applicator versus the use of a fingertip. J Clin Dent 2009; 20: 131-136.

\section{Quintessential dental uniforms}

Made in Italy, the quality Pastelli uniforms available from RPA Dental encapsulate the essence of dental attire.

Flexible, comfortable and durable, Pastelli garments are everything that dental professionals desire from a work garment.

Not satisfied with just offering what is needed, however, the Pastelli range from

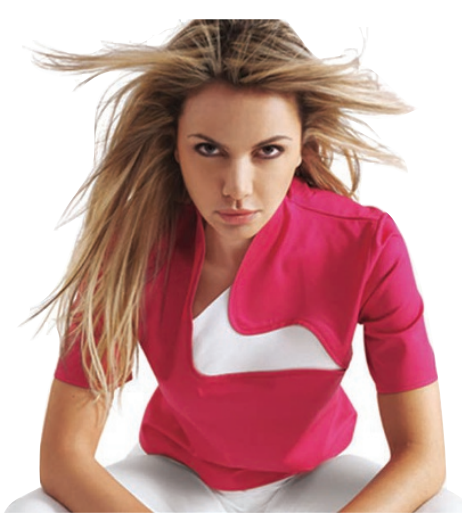
RPA Dental places high importance on style, use of colours, stitching and monitoring quality control. The result? High-end tailoring that is elegant and fashionable. And when you look great, you feel great.

With over 40 pages, the brochure is now available to download from www.dental-equipment.co.uk/uniforms.

It features both traditional and modern uniforms for both genders in a range of colours, sizes and fits. A range of stylish and comfortable shoes are also available, as well as staple accessories such as hats and belts.

To see how RPA Dental can transform your dental practice, call 08000933975 or visit www.dental-equipment.co.uk.

\section{Protect dental unit water lines}

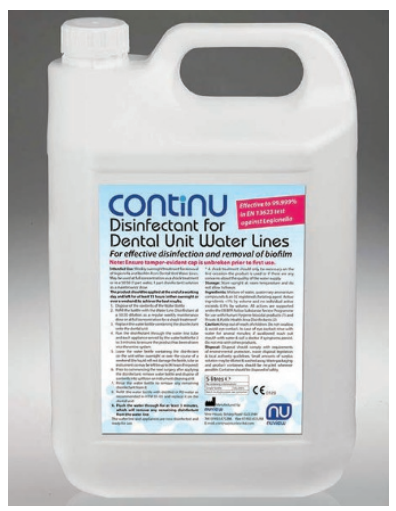

Dedicated to offering top products that benefit the dental practice,

Nuview manufactures and distributes the Continu Disinfectant for Dental Unit Water Lines.

The solution, which is both fully compliant with HTM 01-05 requirements and Class IIa CE marked in accordance with the Medical Devices Directive, is one of the leading non-corrosive, gentle, water-based disinfectants for dental water lines on the market.

Independently proven to be $99.999 \%$ effective against Legionella to European test Standard EN 13623, the alcohol free solution is also extremely efficient, not to mention long-lasting - each chair can be treated weekly rather than with continuous dosing.

Consequently, the solution encourages time efficiency and reduced cost. Plus, it means the product is removed from the system after application so the disinfectant does not enter a patient's mouth during treatment.

To find out more on how the Continu Disinfectant for Dental Unit Water Lines can benefit both your patients and practice, contact Nuview for a free user guide today on 01453872266 or visit www.nuview.co

\section{A versatile production powerhouse}

Over the last 20 years, dentistry has made the move from more traditional, labour-intensive methods to the horizons of digital dental production. With the production of restorations such as crowns, implant abutments and partial frameworks now being produced using automated, labour-saving processes, Roland DG is offering labs who wish to bring their business to the new age the chance to see exactly what embracing digital workflow can do for their profits, and their clients.

Developed by Roland DG's industry experts, the DWX-51D offers the best of both worlds: efficient, compact, fast production with the high-quality finish you'd expect from a hand-crafted output. Designed for the milling of zirconia, wax, PMMA, composite resin and PEEK, the DWX-51D is a versatile production powerhouse for any lab working within the dental market.

To help dental labs see the benefits of the digital evolution, Roland DG has created a DWX-51D ROI calculator designed to provide labs with a bespoke estimation of the profit their lab could benefit from, for the five years following an investment. The ROI calculator details the amount that bringing their lab into the digital age can save their business both in terms of technician hours and financial savings, proving that the DWX-51D is an attractive prospect to any lab looking to expand their offerings and increase their workflow potential.

To request a bespoke ROI calculation for the DWX-51D ROI, visit http:// www.rolanddg.co.uk/dwx-51d_roi/.

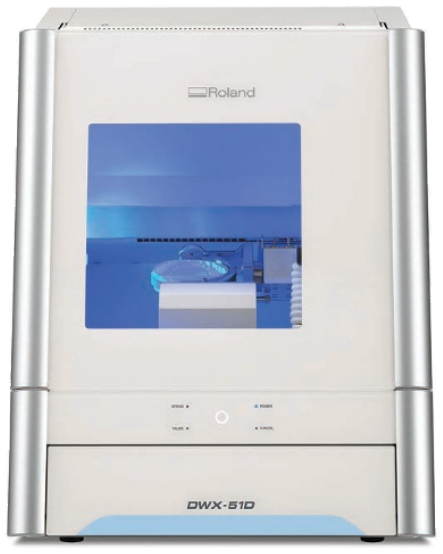

